\title{
Identification of the Best Germination Indices Represents Seed Quality Status in Unaged and Aged Onion Seeds
}

\author{
Sunil Kumar1, Sudipta Basu ${ }^{1 *}$, Anjali Anand ${ }^{2}$, \\ Sandeep Kumar Lal ${ }^{1}$ and Bhoopal Singh Tomar ${ }^{3}$
}
${ }^{1}$ Division of Seed Science and Technology, ${ }^{2}$ Division of Plant Physiology, ${ }^{3}$ Division of Vegetable Science, ICAR-Indian Agricultural Research Institute, New Delhi, India

*Corresponding author

\begin{tabular}{|c|}
\hline Keywords \\
\hline $\begin{array}{l}\text { Germination } \\
\text { Indices, Unaged and } \\
\text { Aged Onion Seeds, } \\
\text { Seed Quality }\end{array}$ \\
\hline Article Info \\
\hline $\begin{array}{l}\text { Accepted: } \\
\text { 10 January } 2021 \\
\text { Available Online: } \\
\text { 10 February } 2021\end{array}$ \\
\hline
\end{tabular}

Current investigation was conducted to identify the best germination indices that represents seed quality status in unaged and aged onion seeds. Fresh seeds of seventeen onion varieties were preconditioned and subjected to accelerated ageing at $42{ }^{\circ} \mathrm{C}$ and $100 \%$ $\mathrm{RH}$ for six days. The results showed varied response of seed germination indices to ageing; germination percent (GP), time to 50 percent germination $\left(\mathrm{T}_{50}\right)$, mean germination time (MGT), coefficient of velocity of germination (CVG), Timson's index (TI), germination index (GI) and seed vigour index-I (SVI-I). GP alone was not able to explain the performance of seeds. MGT, CVG and $\mathrm{T}_{50}$ overestimated the speed of germination in aged seeds compared to control. However, the positive correlation between germination index, Timson's index and seedling vigour index-I in control, and negative correlation in aged seeds reiterated the suitability of germination index and Timson's index for the assessment of germination performance in aged seeds. The study concluded that the germination index and Timson's index were the best indices for the assessment of the germination performance compared to coefficient of velocity of germination, mean germination time, time to fifty percent germination and final germination percent.

\section{Introduction}

Seed germination and vigour are highest at physiological maturity (Tekrony and Egli, 1997) but seeds are seldom planted immediately after harvest and are stored under variable durations and conditions. Onion seeds in general are stored for 6-8 months after harvested until next planting season but frequent fluctuations in temperature and relative humidity under hot and humid subtropical regions of India leads to its poor storability (Ellis and Roberts, 1977; Brocklehurst 1985; Rao et al., 2006; Suma et al., 2013). The reduction in germination performance of onion seed is attributed to its chemical composition (lipid content: 22-26\%) and fragile seed coat (cracks at hilum end) which favors higher lipid peroxidation and fungal incidence (Brocklehurst, 1985; Mohamed-Yasseen et al., 1996; Amalfitano et al., 2019). 
According to ISTA (2019) seed germination is "the emergence and development from the seed embryo of those essential structures that indicate the seeds ability to produce a normal plant under favorable conditions". Successful germination and establishment of seedling requires the seed to be placed in favorable conditions i.e. water, temperature, light and oxygen. To compute the results of standard germination and emergence test, various mathematical expressions are being used which consider the final germination percentage, time taken for germination /speed of germination. And not alone final germination percent, speed or time spread represent the correct way to get indices calculated, but the "high or low germination events" also have influence (Kader, 2005). These germination events highlight the vigour and stress resistance of the seed lots (Kader and Jutzi, 2002). Majority of the reviews studied considerable germin ability for summarizing the outcomes of research but seed germination is a dynamic process it takes into account many quantitative parameters, germination process demands measurement based on time, rate, synchrony and homogeneity (Ranal \& Santana, 2006; Labouriau, 1983;Brown \& Mayer 1988). Analysis of seed germination can be done by different ways; first, calculating the final germination percentage. Second, formulae for calculating the time taken to achieve final germination percent of seed lot, third, formulae correlating time and final germination percent. These can be used to analyse the different aspects to know how dynamic the germination process is.

The germination indices are important to the seed physiologists and seed technologists to predict successful stand establishment in agricultural field or experimental plots, and to the ecologists for prediction of dynamics of germination process that helps in study of plant species population which is distributed over period of time. The aim of the current investigation is to identify the best germination indices that represents seed quality status in unaged and aged onion seeds.

\section{Materials and Methods}

\section{Seed material}

Freshly harvested seeds (2018-19) of seventeen onion varieties produced at ICARIndian Agricultural Research Institute, New Delhi (Pusa Riddhi, Pusa Red, Pusa Madhavi, Pusa Early Grano), ICAR-Indian Institute of Horticultural Research, Bengaluru (Arka Pragati, Arka Kalyan, Arka Bheem, Arka Ujjwal, Arka Niketan), ICAR-Directorate of Onion and Garlic Research, Pune (Bhima Kiran, Bhima Shakti, Bhima Shwetha, Bhima Shubhra, Bhima Super) and National Horticultural Research and Development Foundation, New Delhi (NHRDF Red, Agrifound Dark Red, Agrifound Light Red) were used for the study.

\section{Artificial ageing}

The initial moisture content of fresh onion seeds ranged from $4-7 \%$ which were brought to $13-15 \%$ by conditioning seeds for three days with saturated solution of sodium chloride $(40 \mathrm{mg} / 100 \mathrm{ml})$ in desiccators $(76 \%$ R. H.). Seedlots were artificially aged by maintaining temperature $\left(42^{\circ} \mathrm{C}\right)$ and relative humidity $(100 \%)$ throughout the ageing period in desiccators for six days and an unaged control was used for comparative studies. After ageing treatment, the seeds were dried back to their initial moisture content and used for further studies.

\section{Germination test}

Four replicates of hundred seeds were placed on top of paper in a Petridish and placed in walk in germinator chambers maintained at 
$20^{\circ} \mathrm{C}$ and $100 \% \mathrm{RH}$ for twelve days (ISTA, 2019). The number of normal seedlings was counted after twelve days and germination percent was calculated.

\section{Germination indices}

\section{Different germination indices were used to evaluate seed quality}

Germination percent: (No. of normal seedling/ No. of seeds) $* 100$

$\mathrm{T}_{50}$ (Time to 50 percent germination): It is the time required to achieve $50 \%$ of final/ maximum germination (Coolbear et al., 1984).

$\mathrm{T}_{50}=\mathrm{Ti}+(\mathrm{N}+1 / 2-\mathrm{Ni})(\mathrm{Tj}-\mathrm{Ti}) / \mathrm{Nj}-\mathrm{Ni}$

Where, $\mathrm{T}_{50}$ is the median germination time, $\mathrm{N}$ is the final number of germinated seeds and $\mathrm{Ni}$ and $\mathrm{Nj}$ are the total number of seeds germinated in adjacent counts at time $\mathrm{Ti}$ and $\mathrm{Tj}$ respectively, when $\mathrm{Ni}<\mathrm{N}+1 / 2<\mathrm{Nj}$.

Mean germination time (MGT):It is the average length of time required for maximum germination of a seed lot(Czabator, 1962).

$\mathrm{T}=\sum \mathrm{ki}=1 \mathrm{NiTi} / \sum \mathrm{ki}=1 \mathrm{Ni}$

Where, $\mathrm{Ti}$ is the time from the start of the experiment to the ith observation, $\mathrm{Ni}$ is the number of seeds germinated in the ith time (not the accumulated number, but the number correspondent to the ith observation) and $\mathrm{k}$ is the last time of germination. It is the inverse of mean germination rate $(\mathrm{V}) . \mathrm{T}=1 / \mathrm{V}$

Coefficient of velocity of germination $(\mathrm{CVG})$ : It is calculated as per Labouriau, 1983

$\mathrm{CVG}=\mathrm{N} 1+\mathrm{N} 2+\cdot+\mathrm{Nx} / 100 \times \mathrm{N} 1 \mathrm{~T} 1+\cdot \mathrm{NxTx}$

$\mathrm{N}=$ No. of seeds germinated each day, $\mathrm{T}=$ No. of days from seeding corresponding to $\mathrm{N}$

Germination index (George):It is calculated as per the equation given by Goodchild and walker, 1971.

$\mathrm{GI}=(12 * \mathrm{x} 1)+(11 * \mathrm{x} 2)+\cdots+(1 * \mathrm{x} 12)$

Where, $\mathrm{x} 1, \quad \mathrm{x} 2 \ldots \mathrm{x} 12=$ no, of seeds germinated on day 1,2 . ..until $12^{\text {th }}$ day, $12,11 \ldots 1=$ weights given to the number of germinated seeds on the first, second and subsequent days, respectively.

Modified Timson germination index (TI)- It is estimated as Timson's index $\Sigma$ k divided by the sum of partial germination percentages (Ranal and Santana, 2006).

$\sum k \bmod =\sum k / \sum_{i=1}^{k i} g i$

\section{Seedling vigour index-I}

After taking the final count of germination test, ten normal seedlings from each replication were selected, seedling length was measured and expressed in centimeters $(\mathrm{cm})$. The seedlings were dried overnight at $80 \pm 1$ ${ }^{\circ} \mathrm{C}$ and weighed for dry weight estimation. Vigour indices was calculated by the procedure as suggested by the Abdul-Baki and Anderson (1973).

Vigour index I = Germination $(\%) \times$ Seedling length

\section{Data analysis}

MVApp (Julkowska et al., 2019), a multivariate analysis application was used to conduct principal component analysis. Pearson correlation coefficients between selected germination indices was done. The ANOVA test, complemented by a pairwise Tukey's HSD test was used to examine significant differences among the different 
clusters.

\section{Results and Discussion}

The germination per cent of seventeen onion varieties was ranged from 91-100 per cent in unaged seeds, except in Agrifound Dark Red (87 per cent). However, in aged seeds, a significant decline in the germination percentage was recorded which ranged from 55-76 per cent (Table 1).

The changes reported by seed ageing on the germination indices are presented in the Table 1. All the indices recorded a significant decline with ageing however, time to 50 per cent germination and mean germination time were exceptions. The time to 50 percent germination $\left(\mathrm{T}_{50}\right)$ ranged from $1.64-5.28$ days in unaged seeds whereas, the aged seeds values spanned between 2.17 - 3.33 days. Similar trend was observed with respect to mean germination time which ranged from $2.33-5.86$ days in unaged seeds. However, the aged seed values ranged from $2.69-4.03$ days (Table 1).

The higher values of coefficient of velocity of germination were observed in unaged seeds,which ranged from 17.09 - 43.05. However, a substantial decrease was recorded in aged seed values ranging from 24.94 37.29 (Table 1).Germination index (George)and Timson index showed a similar trend and a significant decline was observed in aged seeds compared to unaged seeds.

Germination index values ranged from 20.67 - 180.00 in unaged seeds, however for the aged seeds, values spanned between 44.00 74.67. Similarly, for Timson index, the unaged seeds recorded values in the range of41.33 -360.00, however, aged seeds showed a decline in values ranging from 88.00 - 148.67.SVI-I of unaged seeds ranged from $743.06-1204.17$ but progression of ageing to six days led to substantial decline in SVI-I which ranged from $190.62-593.64$ (Table 1).

\section{Correlation studies}

\section{Unaged seeds}

In present study unaged seeds recorded no correlation between the germination percent and other germination indices. However, the highest correlations significance was seed vigour index-I with germination index $(r=0.52)$ and Timson index (r=0.52) (Fig. 1a).

\section{Aged seeds}

A highly positive and meaningful correlation was observed between germination per cent and seed vigour index-I $(r=0.74)$. A negative correlation was recorded between SVI-I with germination index $(\mathrm{r}=-0.49)$ and Timson index (r=-0.49) (Fig. 1b).

\section{Principal component analysis}

\section{Unaged seeds}

PCA was performed to examine the number of most informative principal components for the seven variables that accounts for most variability in the data for unaged seeds of seventeen onion varieties. The two principal components (PC1 and PC2) taken together comprised 92.5 per cent(Fig.2a)of the variability in the original data. PCA biplot defined PC1 (75.5 per cent) and PC2 (17 per cent) which altogether explained 92.5 per cent of total variation for seven germination indices (variables)(Fig. 2a). The variables namely Timson's index, germination index, CVG, $\mathrm{T}_{50}$ and MGT were the major contributors to PC1 (Fig. 3a), and for the PC2 germination percent and seedling vigour index-Iwere the major contributors (Fig. 3b). 
Table.1 Changes in the germination indices of unaged and aged seeds of seventeen onion varieties

\begin{tabular}{|c|c|c|c|c|c|c|c|c|c|c|c|c|c|c|}
\hline \multirow[t]{2}{*}{ Variety } & \multicolumn{2}{|c|}{ Germ Percent } & \multicolumn{2}{|c|}{$\mathbf{T}_{\mathbf{5 0}}$} & \multicolumn{2}{|c|}{ MGT } & \multicolumn{2}{|c|}{ CVG } & \multicolumn{2}{|c|}{ GI } & \multicolumn{2}{|c|}{ TimsonsIndex } & \multicolumn{2}{|c|}{ SVI-I } \\
\hline & Unaged & Aged & Unaged & Aged & Unaged & Aged & Unaged & Aged & Unaged & Aged & Unaged & Aged & Unaged & Aged \\
\hline Arka Pragati & $95(76.15)$ & $61(48.89)$ & 3.24 & 2.54 & 3.88 & 3.02 & 25.80 & 33.04 & 108.33 & 74.33 & 216.66 & 148.66 & 743.06 & 400.64 \\
\hline Arka Kalyan & $97(77.75)$ & $71(56.91)$ & 4.42 & 2.55 & 4.71 & 3.07 & 21.24 & 32.55 & 80 & 71 & 160 & 142 & 924.09 & 364.64 \\
\hline Arka Ujjwal & $96(76.95)$ & $59(47.29)$ & 1.88 & 2.44 & 3.04 & 3.11 & 33.06 & 32.08 & 146.33 & 69 & 292.66 & 138 & 830.48 & 407.45 \\
\hline Arka Bheem & $99(79.36)$ & $72(57.71)$ & 1.83 & 2.47 & 2.78 & 3.23 & 36.16 & 30.98 & 160.66 & 63.33 & 321.33 & 126.66 & 961.80 & 421.68 \\
\hline Arka Niketan & $95(76.15)$ & $40(32.06)$ & 4.86 & 2.25 & 5.52 & 3.01 & 18.11 & 33.60 & 67.33 & 42 & 134.66 & 84 & 793.84 & 190.62 \\
\hline NHRDF RED & $91(72.94)$ & $63(50.50)$ & 4.56 & 2.27 & 5.38 & 2.88 & 18.58 & 35.12 & 69.33 & 37.66 & 138.66 & 75.33 & 1002.36 & 392.61 \\
\hline ADR & 87 (69.82) & $55(44.08)$ & 2.08 & 2.16 & 3.44 & 2.68 & 29.04 & 37.28 & 117.66 & 74 & 235.33 & 148 & 848.61 & 457.45 \\
\hline ALR & 99 (79.36) & $68(54.51)$ & 4.81 & 2.44 & 5.48 & 3.11 & 18.21 & 32.90 & 65.66 & 39 & 131.33 & 78 & 922.92 & 428.67 \\
\hline Pusa Red & $97(77.75)$ & $71(56.91)$ & 5.27 & 2.53 & 5.85 & 3.33 & 17.08 & 30.51 & 59.66 & 23 & 119.33 & 46 & 874.09 & 491.02 \\
\hline Pusa Riddhi & $96(76.95)$ & $69(55.31)$ & 4.51 & 2.47 & 5.23 & 3.44 & 19.11 & 29.24 & 55.33 & 43.66 & 110.66 & 87.33 & 960.90 & 392.26 \\
\hline P. Madhavi & 99 (79.36) & $59(47.29)$ & 5.26 & 2.53 & 5.79 & 3.40 & 17.27 & 29.50 & 54.66 & 20.66 & 109.33 & 41.33 & 862.00 & 406.06 \\
\hline PEG & $96(76.95)$ & $57(45.69)$ & 4.60 & 2.68 & 5.18 & 3.61 & 19.27 & 27.97 & 52 & 51 & 104 & 102 & 1038.33 & 339.63 \\
\hline B. Kiran & 97 (77.75) & $76(60.92)$ & 1.64 & 3.32 & 2.32 & 4.02 & 43.04 & 24.93 & 180 & 44 & 360 & 88 & 1204.17 & 517.49 \\
\hline B. Super & $93(74.14)$ & $68(54.51)$ & 1.79 & 3.25 & 2.55 & 3.96 & 39.24 & 25.42 & 161 & 45.33 & 322 & 90.66 & 961.72 & 456.02 \\
\hline B. Shakti & 99 (79.36) & $73(58.51)$ & 1.71 & 3.17 & 2.49 & 3.91 & 40.15 & 25.72 & 174 & 44 & 348 & 88 & 1129.52 & 551.60 \\
\hline B. Shubhra & $100(80.16)$ & $69(55.31)$ & 1.76 & 2.68 & 2.86 & 3.56 & 34.93 & 28.15 & 159.66 & 50.66 & 319.33 & 101.33 & 1139.55 & 593.64 \\
\hline B. Shwetha & $100(80.16)$ & $71(56.91)$ & 1.71 & 2.66 & 2.58 & 3.54 & 38.71 & 28.32 & 172.33 & 55.33 & 344.66 & 110.66 & 1178.15 & 457.24 \\
\hline Mean & 77.14 & 51.96 & 3.29 & 2.61 & 4.06 & 3.35 & 27.56 & 30.43 & 101.05 & 59.64 & 202.11 & 119.29 & 963.27 & 427.57 \\
\hline SEm & 0.66 & 1.73 & 0.36 & 0.08 & 0.33 & 0.09 & 2.32 & 0.84 & 14.80 & 2.53 & 29.61 & 5.07 & 33.17 & 21.82 \\
\hline C.D. (0.05) & 2.74 & 7.14 & 1.51 & 0.34 & 1.36 & 0.39 & 9.60 & 3.49 & 61.06 & 10.47 & 98.12 & 18.93 & 136.80 & 90.00 \\
\hline
\end{tabular}


Fig.1 The figure shows the pearson correlation coefficients between selected traits of unaged (a) and aged seeds (b) of onion varieties. The color of the number reflects the strength of the correlation. The non-significant correlations, with the $p$-value above 0.05 are indicated with a cross in the individual cells

a.

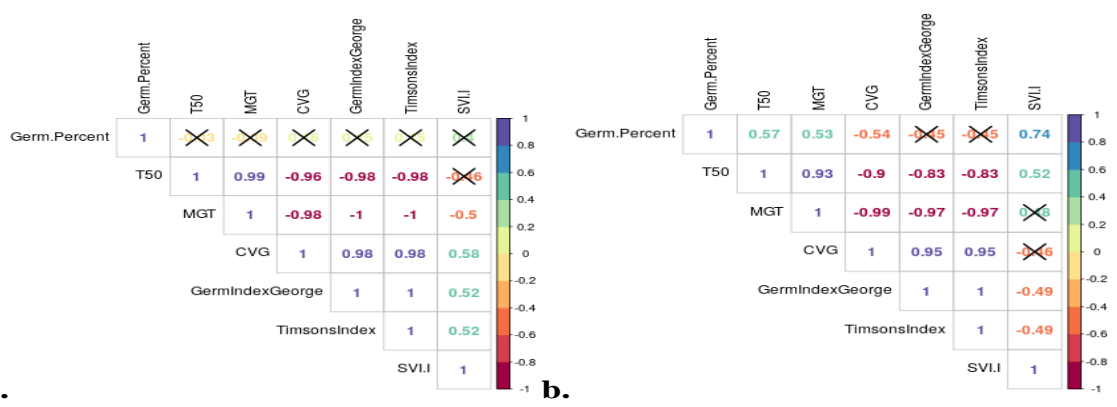

Fig.2 Biplot trait contributions to PC 1 and PC 2 in unaged (a) and aged seeds (b) of seventeen onion varieties. The contribution to PC 1 is shown on the $\mathrm{x}$-axis, while the contribution to PC 2

is on the y-axis. The values between the brackets indicate the percentage of the variance explained by the individual PCs. Each trait's contribution to the selected principal component is indicated by the length and color of the arrow. PCA was performed on raw data using the following traits: Germination percent $\mathrm{T}_{50}$, MGT, CVG, Germination Index (George), Timson'sIndex, Seed vigor index-I

a.

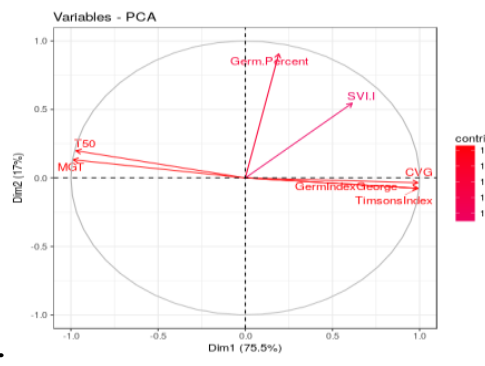

b.

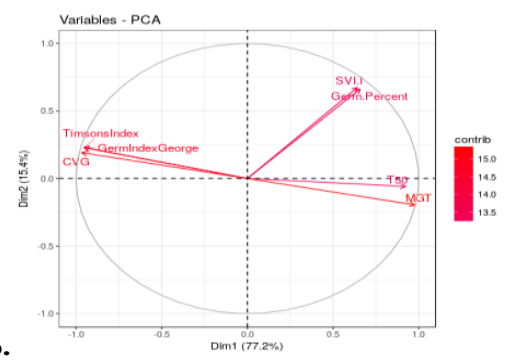

Fig.3 Contributions of the selected traits to PC 1(a) and PC 2 (b) in unaged. Traits are shown on the $\mathrm{x}$-axis, while the degree of contribution to PC 1 is on the y-axis. The red line represents a reference of the expected value if the contribution was uniform. For a given PC, any trait with a contribution above the reference line can be considered an important contributor to that PC. PCA was performed on raw data using the following traits: ( $\mathrm{T}_{50}, \mathrm{MGT}, \mathrm{CVG}$, Germination Index,

Timson Index, SVI-I and Germination percent)
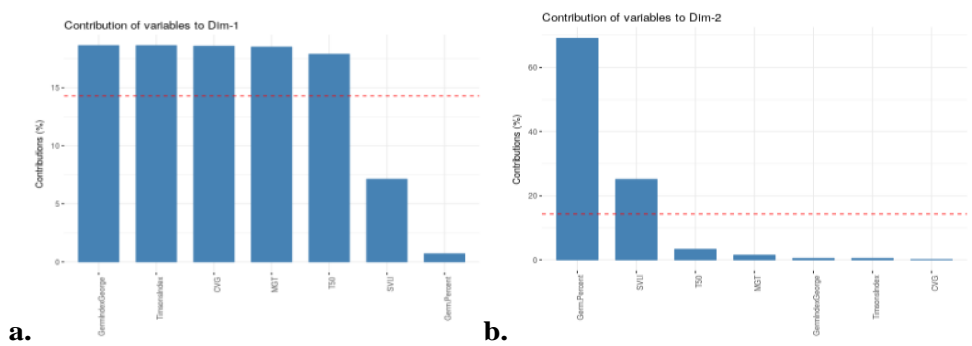
Fig.4 Contributions of the selected traits to PC 1(a) and PC 2 (b) inaged seeds. Traits are shown on the x-axis, while the degree of contribution to PC 1 is on the $y$-axis. The red line represents a reference of the expected value if the contribution was uniform. For a given PC, any trait with a contribution above the reference line can be considered an important contributor to that PC. PCA was performed on raw data using the following traits: $\left(\mathrm{T}_{50}, \mathrm{MGT}, \mathrm{CVG}\right.$, Germination Index,

Timson Index, SVI-I and Germination percent)
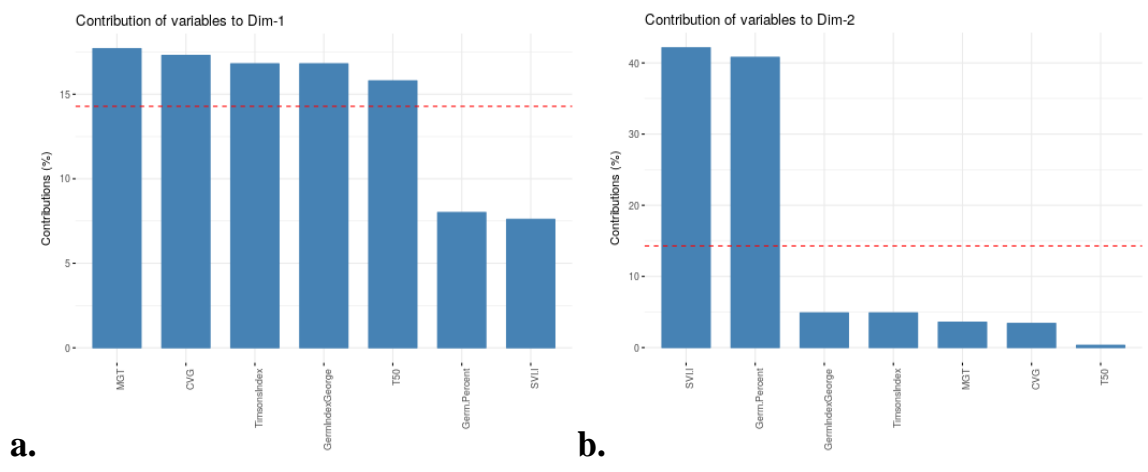

The resulting PCA biplot revealed the correlation and stability between the different germination indices used. In unaged seeds, the Timson's index, germination index and CVG were positively correlated to germination percent and the seed vigour index-I, however $\mathrm{T}_{50}$ and MGT were negatively correlated to the both germination per cent, seed vigour index-I and Timson's index, germination index and CVG. This was also confirmed by the pearson correlation test (Fig. 1a).

\section{Aged seeds}

The two principal components (PC1 and PC2) taken together comprised 92.6 per cent (Fig.2a) of the variability in the original data. PCA biplot defined PC1 (77.2 per cent) and PC2 (15.4 per cent) which altogether explained 92.6 per cent of total variation for seven germination indices (variables) (Fig. 2b). The variables namely MGT, CVG, Timson's index, germination index and $\mathrm{T}_{50}$ were the major contributors to PC1 (Fig. $4 \mathrm{a})$, and for the PC2 seedling vigour index-I and germination percent were the major contributors (Fig. 4b). Inaged seeds, $\mathrm{T}_{50}$ and
MGT were positively correlated to the germination per cent, seed vigour index-I, however, contrarily, the Timson's index, germination index and CVG were negatively correlated with germination percent and the seed vigour index-I, and also with the $\mathrm{T}_{50}$ and MGT. This was also confirmed by the pearson correlation test (Fig. 1b).

Seed germination indices are among the most important requirements for assessment of effect of any stress on seeds i.e. artificial ageing and abiotic stresses (Boubaker, 1996). Artificial aging treatments (controlled deterioration and accelerated aging) mimic the natural aging process and are widely accepted for studies related to seed longevity (Delouche and Baskin, 1973;Bentsink et al., 2000). The germination indices are significantly impacted by the ageing or the other stresses (Hakim et al., 2010). In current study, different seed germination indices were used for the assessment of the germination performance of unaged and aged onion seeds to select the best germination index.

The germination capacity of the seeds is basically a qualitative data which is converted 
at the final count day as quantitative data, generally percentage (Ranal and Santana, 2006). However, not alone final germination percent, speed or time spread represent the correct way to get indices calculated, but the "high or low germination events" also have influence (Kader, 2005). Attempts also have been made to find mathematical formula that incorporates two or more distinct indices/attributes of germination (Bewley and Black, 1994). In present study, germination percent alone was not able to explain the performance of seeds. For example, Aged seeds of P. Riddhi and B. Shubhra although exhibited similar germination per cent $(69 \%)$ but their vigour index-I was significantly different which was 392.26 (P. Madhavi) and 593.64 (B. Shubhra) (Table 1). Similarly, other time dependent indices also can be included along with germination for a better interpretation of the germination process.

Mean germination time (MGT), coefficient of velocity of germination and time to $50 \%$ germination $\left(\mathrm{T}_{50}\right)$ are the measures to study time spread and the rate/speed of seed germination (Soltani et al., 2015). The $\mathrm{T}_{50}$ doesn't consider the time from seed imbibition to particular germination per cent and varies with the final germination percentage achieved. When final germination percent varies amongst the treatments, the t50 could not be used for different populations (Bewley, 2013). However, in case of MGT, as it doesn't take into account the time to a specific germination percent, it may overestimate the control and treated seeds (Soltani et al., 2015). Similarly, in current study, A. Niketan achieved 95 and 40 per cent in control and aged seeds respectively. MGT value was 5.52 days in control and 3.01 days in aged seeds for the same variety, it overestimated speed of germination in aged seeds compared to control, as MGT doesn't consider time to achieve specific germination percent. CVG is represented as reciprocal of
MGT, so this could also cause an overestimate the speed of germination as its observed in case of A. Niketan (Control=18.11, aged=33.60).

Timson index and germination index are the germination indices that consider final germination per cent and germination rate for its assessment, so these are considered as precise methods to calculate the germination performance Goodchild \& Walker (1971). As observed in the present study, these germination indices also showed positive correlation with the seedling vigor index-I and it was in conformity with the findings of Brown and Mayer (1988).

Furthermore, principal component analysis and correlation studies assisted the search for the germination indices which explained the ageing in seeds. The germination index and Timson's index clearly explained the response of seeds to ageing. The positive correlation between germination index, Timson's index and seedling vigour index-I in control, and negative correlation in aged seeds. This study reiterated the suitability of germination index and Timson's index for the assessment of germination performance in aged seeds. These results were in conformity with the findings of Caloneet al., 2020.

The study concluded that the germination index and Timson's index were the best indices for the assessment of the germination performance compared to coefficient of velocity of germination, mean germination time, time to fifty percent germination and final germination percent.

\section{Acknowledgements}

The Senior Research Fellowship provided by ICAR-Indian Agricultural Research Institute, New Delhi, India to the first author during his doctoral studies is acknowledged. 


\section{Contributions}

SB and AA conceptualized the hypothesis, designed the experiment and finalized the manuscript. SK performed the experiment, analysed the data and drafted the manuscript. SK carried out data analysis. All authors reviewed the manuscript.

\section{References}

Calone, R., Sanoubar, R., Noli, E., \&Barbanti, L. (2020). Assessing Salicornia europaea Tolerance to Salinity at Seed Germination Stage. Agriculture, 10(2), 29.

ISTA (2019). International Rules for Seed Testing. Bassersdorf: International Seed Testing Association.

Ranal, M. A., \& Santana, D. G. D. (2006). How and why to measure the germination process?. Brazilian Journal of Botany, 29(1), 1-11.

Kader, M., \& Jutzi, S. (2001). Drought, heat and combined stresses and the associated germination of two sorghum varieties osmotically primed with $\mathrm{NaCl}$. Phytopathology, 3, 22-24.

Kader, M. A. (2005). A comparison of seed germination calculation formulae and the associated interpretation of resulting data. Journal and Proceeding of the Royal Society of New South Wales, 138, 65-75.

Labouriau, L. G. (1983). A germinação das sementes. Série de Biologia. Monografia, 24.

Brown, R. F., \& Mayer, D. G. (1988). Representing cumulative germination. 1. A critical analysis of single-value germination indices. Annals of Botany, 61(2), 117-125.

Czabator, Felix J. "Germination value: an index combining speed and completeness of pine seed germination." Forest science 8, no. 4 (1962): 386-396.

Goodchild, N. A., \& Walker, M. G. (1971). A method of measuring seed germination in physiological studies. Annals of Botany, 35(3), 615-621.

Abdul-Baki, A. A., \& Anderson, J. D. (1973). Vigor determination in soybean seed by multiple criteria 1. Crop science, 13(6), 630-633.

Julkowska, M. M., Saade, S., Agarwal, G., Gao, G., Pailles, Y., Morton, M.,. .. \& Tester, M. (2019). MVAPP - multivariate analysis application for streamlined data analysis and curation. Plant physiology, 180(3), 1261-1276.

Boubaker, M. Salt tolerance of durum wheat cultivars during germination and early seedling growth. Agric. Medit. 1996, 126, 32-39.

Hakim, M.A.; Juraimi, A.S.; Begum, M.; Hanafi, M.M.; Ismail, M.R.; Selamat, A. Effect of salt stress on germination and early seedling growth of rice (Oryza sativa L.). African J. Biotechnol. 2010, 9, 19111918.

Bentsink, L. et al., Genetic analysis of seedsoluble oligosaccharides in relation to seed storability of Arabidopsis. Plant Physiol. 124 (4), 1595-1604, https://doi.org/10.1104/pp.124.4.1595 (2000).

Delouche, J.C. Baskin, C.C. (1973) Accelerated aging techniques for predicting the relative storability of seed lots. Seed Sci. and Technol.1:427-452.

Bewley, J. D. (1994). Seeds: germination, structure, and composition. Seeds: physiology of development and germination, 1-31.

Soltani, E., Ghaderi-Far, F., Baskin, C. C., \& Baskin, J. M. (2016). Problems with using mean germination time to calculate rate of seed germination. Australian Journal of Botany, 63(8), 631-635.

Bewley, J. D., Bradford, K., \& Hilhorst, H. (2012). Seeds: physiology of development, germination and dormancy. Springer Science \& Business Media. 


\section{How to cite this article:}

Sunil Kumar, Sudipta Basu, Anjali Anand, Sandeep Kumar Lal and Bhoopal Singh Tomar. 2021. Identification of the Best Germination Indices Represents Seed Quality Status in Unaged and Aged Onion Seeds. Int.J.Curr.Microbiol.App.Sci. 10(02): 76-85.

doi: https://doi.org/10.20546/ijcmas.2021.1002.009 